\title{
A Longitudinal Study of Morbidity Pattern and Nutritional status of under Five Children in a Slum Community of Kolkata
}

\author{
Sucharita Maji ${ }^{1}$, Sandip Kumar Ray ${ }^{2}$, Saibendu Kumar Lahiri ${ }^{3}$ \\ ${ }^{I}$ Associate Prof, Dept of Community Medicine, Medical College, Kolkata, \\ ${ }^{2}$ Professor, Dept of Community Medicine, ICARE Institute of Medical Science \& \\ Research \& Dr. Bidhan Chandra Roy Hospital, Haldia \\ ${ }^{3}$ Prof \& Head, Dept of Community Medicine, R. G. Kar Medical College, Kolkata
}

\begin{abstract}
:
Introduction: Nearly one-tenth of the India's population is children under 5 years of age. So the morbidities and under nutrition affecting their health have got bearing on the overall health status of the country. Urban under-served slum dweller children are more vulnerable to infection and under nutrition due to their exposure to unfavourable socio economic and environmental conditions.
\end{abstract}

Objective: To study the morbidity pattern and nutritional status among the under five children residing in urban slum and to find out the association with morbidity and under nutrition.

Methodology: A longitudinal community based observational study was conducted among all under five children (49) - who were followed up once in a fortnight for 12 months. In the study area, under five children were selected by Census method, Episode wise incidence, seasonal variation and association of morbidity with different parameters were calculated. To assess nutritional status weight was measured once in a month and plotted on the then followed ICDS growth chart. Height / length \& wasting were measured once in a month and were compared with NCHS chart.

Result: Both Points prevalence rate and episode based incidence of Acute Respiratory Infection (ARI)) were highest among the morbidities followed by fever \& diarrhea. Seasonal variations were seen in ARI, diarrhea, fever and skin diseases. Incidence of ARI was more in winter and pre winter whereas incidence of diarrhea and fever were more in summer. Skin infection was more in monsoon months. Episodes of Morbidity were associated significantly with high birth order, more number of siblings in the family and less feeding practice during illness. Morbidity was more among children with severe degree of under nutrition as well as having growth faltering. Under nutrition, stunting and wasting were more prevalent among girls.

Conclusion: ARI, fever and diarrhea were the major causes of morbidity. These three diseases and skin infection showed seasonal variation. Morbidity episodes were associated significantly with birth order, number of siblings and feeding practice during illness and severe under nutrition or growth faltering. Girl children were more undernourished, stunted and wasted than boys. In any planning process for improvement of mother and child health these information are very essential.

Key words: morbidity pattern - nutritional status-slum dweller under five children-longitudinal study.

\section{Introduction}

The large and continuous increase in India's urban population and the concomitant growth of the population residing in slums has resulted in overstraining of infrastructure leading to deterioration of public health. According to 2001 census India's total population was $1027015247^{1}$ and $10.7 \%$ of its population was under 5 years of age ${ }^{2}$. So the health status of this vulnerable age group (under-five children) are very much important as both morbidities and the nutritional status affect their health which influences on the overall health status of the country. Therefore, to understand the morbidity pattern and its effect on nutritional status of underfive children residing in slum, the present study was undertaken with the following objectives-

\section{Objectives:}

1. To study the magnitude of the problem of common morbid conditions in the studied population.

2. To assess the nutritional status of the underfive children.

3. To find out the association between morbidity and under nutrition and some socio demographic factors and child caring practices.

\section{Materials and methods}

It is a community based observational longitudinal study, carried out in an urban slum situated at Arpuli Lane which is a field practice area of Medical College, Kolkata. The study was carried out during the 
period from August 2005 to July 2006. All the underfive children belonging to enlisted families (206) were included in the study (Census method). 49 children were followed up for completed 12 months. Ethical clearance from the Calcutta Medical College was obtained and consent was taken from the caregiver of the study population in the designed consent form.

The data was collected in a Pre-designed and pre-tested proforma for baseline information, morbidity events as well as some important factors contributing to morbidities like birth order, immunization status, nutritional status, socio economic status of the families etc. Correct recording of the age of the children were done by using available records like Birth Certificates, hospital discharge certificate of the mothers after institutional delivery, etc or by asking question and comparing it with local calendar events. Anthropometric measurements like weight and height/ length were taken on monthly basis by Salter's weighing machine and steel tape/ Infantometer respectively. Data was collected by interviewing mothers / caregivers and assessing the children once in a fortnight for episodes of morbidities. Clinical assessment for morbidities was restricted only for those morbid under five children, who were found sick at the time of the visits.

Other Important tools used IAP Growth chart, used in ICDS, NCHS charts for weight for age, weight for height and height for age, Stethoscope, Torch etc. Data related to morbidities were expressed in prevalence and incsidence rates. Data related to nutritional status were interpreted with plotting weight on Growth chart or comparing the data with NCHS charts. The associations of morbidity with different socio- demographic, cultural and nutritional factors were analyzed by using chi square test.

\section{Result}

Out of 49 study population, 22 (44.9\%) were male and 27 (55.1\%) were female. Children, mostly, belonged to the age group of $0-11$ months $(26.02 \%)$ followed by $48-59$ months $(24.66 \%)$ at the time of first contact. Majority of the study population belonged to schedule caste $(69.4 \%)$ followed by general caste $(26.5 \%)$ and other backward classes (4.1\%). According to Modified Kuppuswamy Scale majority (45.2\%) of the study population belonged to upper lower socio economic status followed by lower middle $(39.73 \%)$ and upper middle (15.07\%) status. Majority of the mothers $(45.84 \%)$ and fathers $(44.12 \%)$ of the study population were educated up to primary school.

Analyzing the data collected during the first visit, it was found that children suffered from 18 different morbidities. Point prevalence of Acute Respiratory Infection (ARI) and Skin infection were highest (both $33.33 \%$ ) followed by Diarrhoea and fever $(11.11 \%$ each). Other morbid conditions found were worm infestation, measles, injury etc.

Analyzing the one year morbidity data following fortnightly follow up visit it was calculated that Mean number of morbidities were 6.02 episodes per child year. It was also found that male children suffered from 5.68 morbidity episodes per child year whereas female children suffered from 6.3 morbidity episodes per child year. Table 1 shows that ARI was the most common cause of morbidity $(32.20 \%)$ followed by fever $(23.05 \%)$ and diarrhea (21.69\%). Episode wise incidence of ARI was highest (1939 episodes/ 1000 population /year) followed by fever and diarrhoea.

Table 1: episode wise distribution of different morbidities in 12-month period $(n=49)$

\begin{tabular}{|c|c|c|}
\hline Morbidity & No. of episodes (\%) & $\begin{array}{c}\text { Incidence } \\
\text { (episodes/1000 under five } \\
\text { population/year) }\end{array}$ \\
\hline ARI & $95(32.20)$ & 1939 \\
\hline Diarrhea & $64(21.69)$ & 1306 \\
\hline Measles & $2(0.68)$ & 41 \\
\hline Fever & $68(23.05)$ & 1388 \\
\hline Worm & $22(7.46)$ & 449 \\
\hline Skin & $19(6.44)$ & 388 \\
\hline Others & $25(8.48)$ & 510 \\
\hline Total & $\mathbf{2 9 5 ( 1 0 0 )}$ & $\mathbf{6 0 2 1}$ \\
\hline
\end{tabular}

Those children who had no sibling or only one sibling had suffered fewer episodes than who had more than 2 siblings. The finding was statistically significant $\left(\mathrm{x}^{2}=9.84\right.$, degree of freedom, $\left.\mathrm{df}=3, \mathrm{P}<0.05\right)$. First and second birth order children suffered less number of episodes of morbidity than third and more birth order children. The result was statistically significant $\left(\mathrm{X}^{2}=7.24, \mathrm{df}=2, \mathrm{P}<0.02\right)$. Episodes of morbidities were less $(30.77 \%)$ in children who were given same amount of food during illness in comparison to those, who were given less amount of food $(94.12 \%)$. The result was statistically significant $(\mathrm{X} 2=5.56, \mathrm{df}=1, \mathrm{P}<0.02)$. 


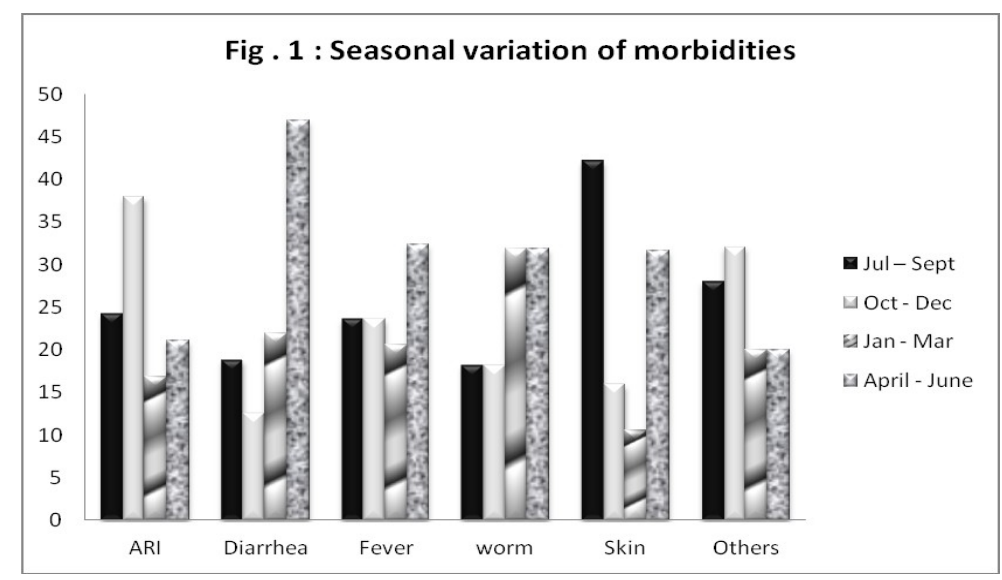

Fig. 1- Multiple Bar diagram shows that majorities of the morbidities occurred in summer (April-June) followed by pre winter (Oct-Dec) and winter months (Jan- Mar). ARI was more prevalent in winter and pre winter whereas diarrhoea and fever were more prevalent in summer. Skin infection was more in monsoon months (Jul-Sept).

$52.05 \%$ of the study population was exposed to passive smoking. Indoor air pollution (having no separate kitchen facilities or smoke outlets) was present in the houses of $78.1 \%$ of the study population. However, no significant association was found among occurrence of ARI and exposure to passive smoking or indoor air pollution.

Only $20.5 \%$ of the mothers were the decision makers regarding the place and time of care seeking of their sick children. Time gap between onset of disease and care seeking was 2 days in most of the cases $(50.7 \%)$ when government health facilities was very close.

After analyzing the baseline data it was found that $21.92 \%$ of the study populations were Undernourished according to NCHS scale. Severe degree of under nutrition $(<-3 \mathrm{SD})$ was found among $6.85 \%$ of the study population. Under nutrition was more prevalent among girl children $(15.01 \%)$ than boys $(6.89 \%)$. Under nutrition was more among 48-59 months age group followed by 24-35 months.

Stunting (height $<-2$ SD according to NCHS scale) height for age was found among $36.99 \%$ of the study population and was more prevalent in 48-59 months age groups. It was found more among girls $(21.92 \%)$ than boys $(15.17 \%)$. Severe degree of stunting $(<-3 \mathrm{SD})$ was seen among $8.22 \%$ of girls and $2.74 \%$ of boys.

Wasting (weight for height $<-2$ SD according to NCHS standard) was seen among $19.18 \%$ of the study population. It was more prevalent among $0-11$ months age groups followed by $24-35$ months age groups. It was also seen more among girls $(15.07 \%)$ than boys $(4.11 \%)$.

All general category children were normally nourished while $29.63 \%$ of SC and OBC children were malnourished. $28.13 \%$ children from upper lower class were malnourished followed by lower middle class (20\%) and upper middle class $(9.09 \%)$.

Analyzing the 12 months data, it was found that under nutrition was more in monsoon (37.5\%) months followed by summer (25\%). This could be due to the effect of higher episodes of morbidity during May, June and September.

Growth monitoring in ICDS growth chart (IAP - approved) was also done for whole study population and 4 of the growth charts are shown here to visualize the effect of morbidity on nutritional status (Fig. 2). Episodes of morbidities were always followed by growth faltering. It was observed that episodes of morbidity were more when there was a growth faltering in children followed by severe degree of malnutrition. Different morbidities were less in children who had normal nutritional status throughout the year. The children with malnutrition suffered more episodes of worm infestation and skin infection. 
Fig. 2 : Growth faltering following repeated infections

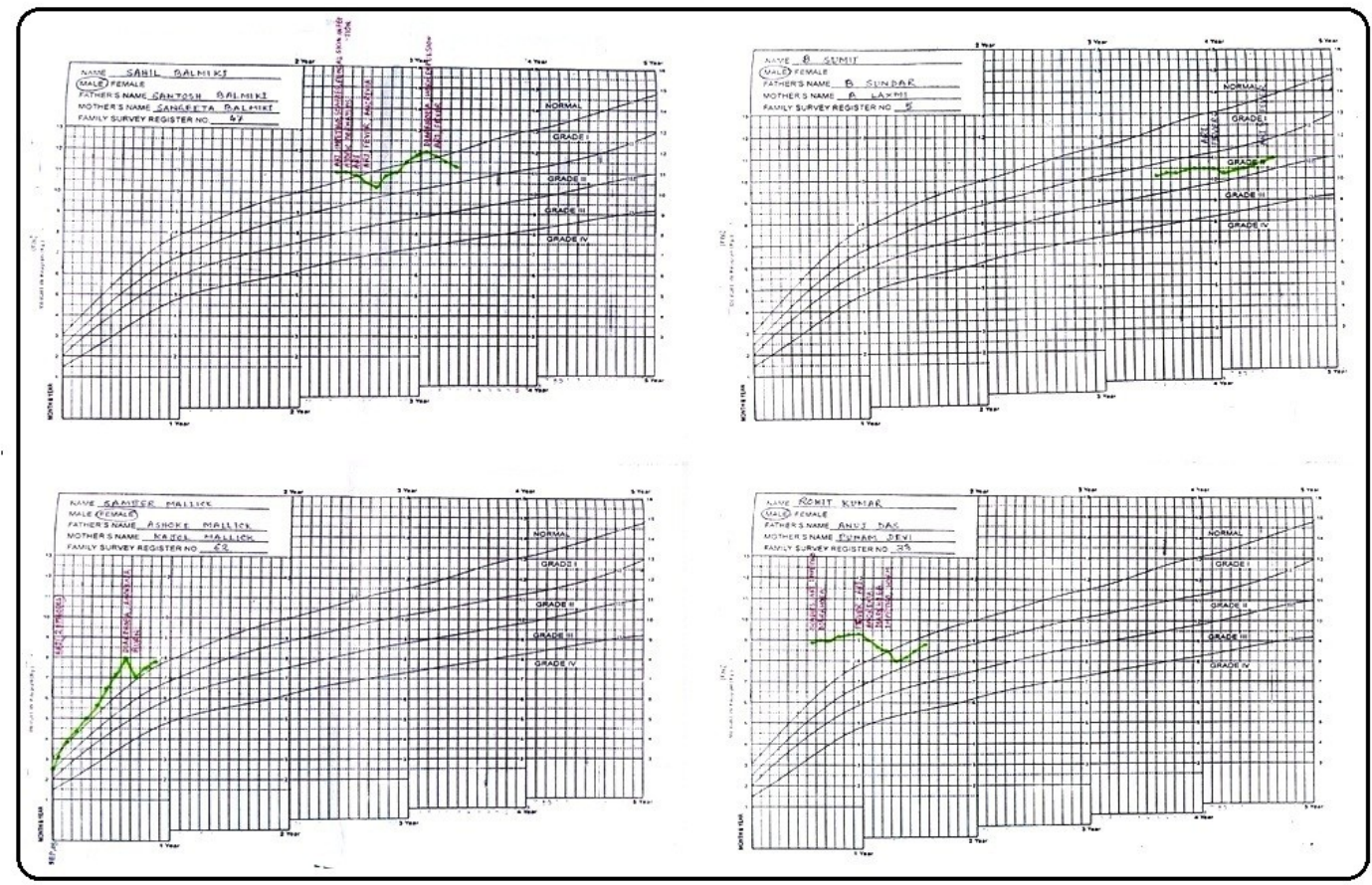

\section{Discussion}

The present study showed that ARI was the most common cause of morbidity followed by fever and diarrhea. Mean episodes of morbidity was 6.02 per child year. ARI was more prevalent in winter and pre winter whereas diarrhoea and fever were more prevalent in summer. Skin infection was more common during monsoon months (Jul-Sept).

In a study carried out earlier, it was shown that, under-five children of urban area suffer from $5-8$ episodes of ARI in a year ${ }^{3}$. Kapil Umesh and Sood A.K. (1989) carried out a cross-sectional study in Faridabad and observed that common morbidities were pyoderma (23.65\%), respiratory infection $(21.18 \%)$, diarrhea (20.05\%), unspecified fever (11.75\%), ear infection (6.58\%) and eye infection $(5.46 \%)$. The maximum episodes of morbidities were recorded in summer season $(39.22 \%)$ followed by Rainy $(31.36 \%)$ and winter season $(30.16 \%)^{4}$. A study conducted by A.K. Sharma et al. in Sunderpur slum area of Varanasi (1989 - 1990) showed that episode rate of ARI among under five children -was 6.11/child/year. ARI accounted for $67 \%$ of all morbidities ${ }^{5}$. Venkatesh et al (1986) in their longitudinal study, of morbidity in under fives found that the incidence of Upper Respiratory Infection (URI), diarrhoea, skin diseases and LRI was highest in the 2nd quarter of the year, i.e. April to June; and least in the 4th quarter i.e. October to December. The incidence of URI reached peak in the month of April ${ }^{6}$. Lang et al (1986) observed that diarrhea and ARI had the highest prevalence i.e. $59 \%$ during rainy season and $73 \%$ during dry season respectively. URI was more frequent $(21 \%)$ during dry season than rainy season $(12 \%)^{7}$.

The findings of the present study corroborated with observation of the study mentioned above. During initiation of the study it was observed that under nutrition, stunting and wasting were present among $21.92 \%$, $36.99 \%$ and $19.18 \%$ among the underfive children respectively. Analyzing the 12 months data, it was found that under nutrition was more in monsoon $(37.5 \%)$ months followed by summer $(25 \%)$. This could be due to the effect of higher episodes of morbidity during May, June and September.

Girl children suffered more episodes of morbidities, under nutrition, stunting and wasting than boys. A study conducted by Bhalani KD. and Kotecha PV. (2002) in Vadodara revealed that the prevalence of moderate to severe malnutrition among girls was $28.4 \%$ as against $16.9 \%$ in boys ${ }^{8}$. Devi Sanayaima $\mathrm{H}$ et al (2003) carried out a cross-sectional study in Imphal and observed that Prevalence of malnutrition was higher in girls $(53.5 \%)$ than in boys $(38.3 \%)^{9}$. Ray S.K. showed that severe degree of malnutrition was 3 times more amongst the pavement dweller girl children than boys ${ }^{10}$. The present study reports had similar observations.

Findings in figure 2 showed that growth faltering was present in all the four growth charts presented. The faltering of growth was present following episode of illness. The Narangwal experiments by Kielmann, A. A., Taylor, C.I. et al on the interactions of nutrition and infection also showed the effect of morbidity and mortality on malnutrition ${ }^{11}$.Pavement dweller study ${ }^{10}$ also showed with the increase in number of illness episodes in last fifteen days, severe degree of malnutrition increased. The present study findings was similar to 
the findings of the above studies. Observation also revealed undernutrition had been linked to higher number of siblings, birth order ${ }^{12,13,14,15}$.

\section{Conclusion}

ARI, fever and diarrhea were the major causes of morbidity. These three diseases and skin infection showed seasonal variation. Morbidity episodes were associated significantly with birth order, number of siblings, and feeding practice during illness and severe under nutrition or growth faltering. Under nutrition, stunting and wasting were found more among girl children than boys. Under nutrition was more in monsoon months followed by summer. This could be due to the effect of higher episodes of morbidity during May, June and September.

Behavour Change through Communication (BCC) could improve the situation by changing behavior as well as by motivating the caregiver for children and also by attending Anganwadi centere regularly. This might change the present scenario.

\section{Reference}

[1]. Govt. of India. Provisional population totals. Census of India 2001. P-1

[2]. School of Health Sciences. Demography and Epidemiology of ageing, Basic Geriatrics, Indira Gandhi National Open University, March 2004; MME-004, Unit 1, Block-1: 5 -15.

[3]. Unicef, The State of World's Children 1998:1-11

[4]. Kapil U., Sood A.K. Morbidity pattern in children below three year attending a rural health centre in Haryana. Indian Pediatrics, June 1989; XXVI: 550-552.

[5]. Sharma AK, Reddi DCS., Dwivedi RR. Descriptive epidemiology of ARI among under 5 children in an urban slum area. IJPH, OctDec, 1999; XXXXII (4):156.

[6]. Venkatesh S., Bansal RD. A longitudinal study of morbidity among underfives children in a semi-urban area. Indian Journal of Community Medicine 1986; 11(1): $11-20$.

[7]. Lang T., Lafaix C., Fassin D., Arnaut I., Salman B., Bardon D., Ezekiel J. Acute Respiratory Infection - A longitudinal study of 151 children in Burkino-Faso. International longitudinal study of 151 children in Burkino-Faso. International Journal of Epidemiology 1986; 15(4): 553 - 559

[8]. Bhalani, KD., Kotecha, PV. Nutritional status and gender differences in the children of less than 5 years of age attending ICDS Anganwadis in Vadodara City. Ind. J. of Community Medicine 2002; 27(3): 124 - 129.

[9]. Devi Sanayaima, H., Singh, Th Achoubo, Brojen AK. Prevalence of protein energy malnutrition of pre-school children and its associated factors in an urban settlement of Imphal East. Journal of Medical Society 2003; 17(2): 45-49.

[10]. Ray SK. Maternal \& Child Health Study of Pavement Dwellers in Calcutta. Report submitted to UNICEF, Calcutta; $1997: 11-56$.

[11]. Kielmann AA., Taylor CI., Desweemer C., Uberoi IS., Takulia HS., Masih M., Vohra S. The Narangwal experiments interactions of nutrition and infection II; Morbidity and mortality effects. Indian Journal of Medical Research, 1978(Suppl.); 68: $21-41$.

[12]. Ray S.K.Biswas A.B, Dasgupta S, Mukherjee D.Kumar S, Biswas B, Joardar G (2000) - Rapid assessment of Nutritional Status \& Dietary Pattern in a Municipal Area: Indian Journal of Community Medicine: 25; 14-18.

[13]. Ray S.K., Kumar S., Biswas A.B. (2000) - A study of dietary pattern, household food security and nutritional profile of underfive children of a community of West Bengal. Journal of Indian Medical Association: 98; 517-524.

[14]. Ray S (2000): Prevention of Malnutrition (Editorial) Journal of Indian Medical Association 98: 510 -511.

[15]. Ray S.K., Halder A., Mukherjee D., Biswas B., Misra R., Kumar S., (2001) - Epidemiology of Undernutrition: Indian Journal of Pediatrics, Vol. 68. 1025 - 1030 . 